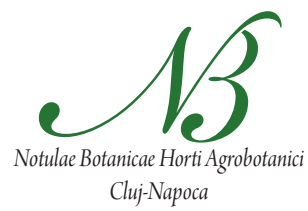

\title{
Comparison of the Mechanical Behaviour of Selected Oilseeds under Compression Loading
}

\author{
David HERAK, Abraham KABUTEY, Monika DIVISOVA, Tereza SVATONOVA \\ Czech University of Life Sciences Prague, Faculty of Engineering, Department of Mechanical Engineering, \\ Kamycka 129, Praha 6, Prague 165 21, Czech Republic; herak@tf.czu.cz
}

\begin{abstract}
The present study provides information about the comparison of mechanical behaviour of selected oil bearing crops namely rapeseeds (Brassica napus L.), sunflower seeds (Helianthus annus L.) and jatropha seeds (Jatropha curcas L.) under compression loading. In this research, the compression device ZDM 50 with a chart recorder and a pressing vessel with diameter $100 \mathrm{~mm}$ were used to determine the relationship between the magnitude of the pressing force and deformation characteristics of the oilseed crops pressed at initial height 80 $\mathrm{mm}$. From the compression test, the amounts of true deformation, maximal deformation energy and compressive force of the pressed samples were calculated and also mathematical equations describing the limit deformation, maximal deformation ratio, energy ratio and oil point deformation ratio were determined. The oil point position on the deformation curve, that is, the first leakage of oil from the pressing vessel of the various oilseeds was determined and compared. Based on the measured amounts rapeseeds achieved the highest values followed by jatropha seed and then sunflower seed. The amount of deformation energy required for the seed deformation gives the indication the amount of energy needed for obtaining the oil from the seed. It was found that the measured amounts as well as the oil point position on the force-deformation curve of the pressed samples showed varying results due to the seeds physical and inherent characteristics.
\end{abstract}

Keywords: compressive force, deformation, energy requirement, mathematical model, oil bearing crops

\section{Introduction}

Rapeseeds (Brassica napus L.), sunflower (Helianthus annus L.) and jatropha (Jatropha curcas L.) are important oilseed crops because it contains oil in large quantity which can be used for various purposes such as biodiesel production (Izli et al., 2009; Khodabakhshian et al., 2010; Sirisomboon et al., 2007). In the literature, considerable information about the mechanical behaviour of the oilseed crops namely rapeseed (Izli et al., 2009; Rusinek et al., 2007; Unal et al., 2009); sunflower seed (Gupta and Das, 1997; 2000; Isik and Izli, 2007; Perez et al., 2007), and jatropha seed (Herak et al., 2010; Karaj and Muller, 2010; Sirisomboon et al., 2007), have been focused on rupture force and deformation characteristics (Fomin et al., 1978; Herak et al., 2011a; 2012; Kabutey et al., 2011; Koegel et al., 1973; Mrema and Mc Nluty, 1985), unlike the mathematical description of the deformation characteristics, limit deformation ratio, maximal deformation ratio, energy ratio and oil point deformation ratio.

In this respect, Herak et al. (2011b) established the tangent curve function to describe the deformation characteristics of pressed mixtures under compression loading. Also a finite element method (FEM) model was used by (Petru et al., 2012) to describe the mechanical behaviour of Jatropha curcas L. seeds under linear compression loading.
On the other hand, oil point determination is an important parameter in oilseed processing. Considering rapeseed, sunflower seed and jatropha seed, not many studies (Faborode and Favier, 1996; Figueiredo et al., 2011; Herak et al., 2010) highlight the oil point determination under compression loading. To design pressing technology with minimum energy efficiency with respect to maximum oil output, it is important to understand in detail the mechanical behaviour of seeds pressed mixture under compression loading (Blahovec and Reznicek, 1980; Fomin, 1978).

The present study investigated the mechanical behaviour of rapeseeds, jatropha and sunflower seeds under compression loading in terms of deformation, compressive force and deformation energy. Also the study developed the mathematical equations for determining limit deformation, maximal deformation ratio, energy ratio and oil point deformation ratio of the selected oilseeds.

\section{Materials and methods}

\section{Sample}

In the present experiment the used samples were cleaned rapeseeds (Brassica napus L.) and sunflower seeds (Helianthus annus L.) both obtained from Česká Skalice, Czech Republic; and jatropha seeds (Jatropha curcas L.) from Sumatra, Indonesia. The physical properties of the samples in terms of true and bulk densities, weight, 
228

moisture content and porosity were also determined and have been presented in the Tab. 1. The moisture content determination Mc (\% d.b.) of the pressed mixtures (air, free space and seeds in the pressing vessel) was done using moisture equipment Farm Pro (Supertech Agroline, Bogense, Denmark). The weight of the mixtures $\mathrm{m}_{\mathrm{s}}(\mathrm{g})$ was determined using the equipment Kern 440-35N (Kern \& Sohn GmbH, Balingen, Germany). The porosity $\mathrm{P}_{f}(\%)$ (Tab. 1) was calculated from the bulk and true densities using the relationship given by porosity formula (Eq. 1) (Blahovec, 2008):

$$
P_{f}=\left(1-\frac{\rho_{b}}{\rho_{t}}\right) \cdot 100
$$

Where: $P_{f}(\%)$ is the porosity, $\rho_{\mathrm{b}}\left(\mathrm{kg} \mathrm{m}^{-3}\right)$ is the bulk density and it was determined as the weight of the sample $\mathrm{m}(\mathrm{g})$ (Tab. 1) divided by initial volume of pressing vessel $\mathrm{V}=6.283 \cdot 10^{-4} \mathrm{~m}^{3}$ and $\rho_{\mathrm{f}}\left(\mathrm{kg} \mathrm{m}^{-3}\right)$ is the true density and it was determined by hydrostatics method (Blahovec, 2008).

Tab. 1. Determined physical properties of seeds pressed mixture (data in the table are means $\pm S D$ )

\begin{tabular}{cccccc}
\hline $\begin{array}{c}\text { Crops } \\
\text { seeds }\end{array}$ & $\begin{array}{c}P_{\mathrm{t}} \\
\left(\mathrm{kg} \cdot \mathrm{m}^{-3}\right)\end{array}$ & $\begin{array}{c}\mathrm{P}_{\mathrm{b}} \\
\left(\mathrm{kg} \cdot \mathrm{m}^{-3}\right)\end{array}$ & $\begin{array}{c}\mathrm{m}_{\mathrm{s}} \\
(\mathrm{g})\end{array}$ & $\begin{array}{c}\mathrm{M}_{\mathrm{c}} \\
(\% \mathrm{~d} . \mathrm{b} .)\end{array}$ & $\begin{array}{c}\mathrm{P}_{\mathrm{f}} \\
(\%)\end{array}$ \\
\hline Rapeseeds & $1080 \pm 2$ & $716 \pm 4$ & $449.75 \pm 1.12$ & $6.8 \pm 0.1$ & $33.7 \pm 0.5$ \\
Sunflower & $885 \pm 3$ & $449 \pm 4$ & $282.25 \pm 0.96$ & $6.2 \pm 0.2$ & $49.2 \pm 0.6$ \\
Jatropha & $971 \pm 3$ & $386 \pm 5$ & $242.25 \pm 1.01$ & $5.7 \pm 0.1$ & $60.9 \pm 0.6$ \\
\hline
\end{tabular}

$\rho_{t}$-true density, $\rho_{b}$-bulk density, $m$-mass of pressed mixture, $M_{c}$-moisture content of the pressed mixture in dry basis, $\mathrm{P}_{\mathrm{f}}$-porosity of pressed mixture

\section{Compression test}

Compression devices namely ZDM 50 (VEB, Dresden, Germany), pressing vessel with inner diameter $\mathrm{D}=$ $100 \mathrm{~mm}$ (Fig. 1) were used to determine the relationship between the magnitude of the pressing force and deformation of pressed mixtures initial pressing height of $\mathrm{H}=80$ $\mathrm{mm}$. Also the pressing vessel has 16 holes at the bottom of diameter $3.5 \mathrm{~mm}$ where the oil passes. The pressing force was set between the range $0 \mathrm{kN}$ and $250 \mathrm{kN}$ to measure the deformation of the samples. The mixtures were pressed under the temperature condition of $20^{\circ} \mathrm{C}$ and the pressing rate of $1 \mathrm{~mm} \cdot \mathrm{s}^{-1}$. The experiment was repeated for each pressed mixture three times and averaged values were used in further calculations. Individual points of measurement were digitally recorded and analyzed with each new addition of deformation of $0.5 \mathrm{~mm}$.

\section{Oilpoint}

The oil point position on the pressing force-deformation curve that is the first leakage of oil from the pressing vessel was determined optically during the compression test.

\section{Maximal deformation}

Maximal deformation $\mathrm{x}_{\max }(\mathrm{mm})$ is the deformation at which the experiment was stopped. This means the amount of seed deformation directly corresponds to the amount of compressive force required for the deformation of the seed.

\section{Maximal deformation energy $E(J)$ and energy at oil point Eo (J)}

Under the force-deformation curve where compression was completed for the deformation of the seed and at the point where the first oil point was noticed on the curve respectively showed the amount of energy used. These amounts of energy were calculated using the software Engauge Digitizer 4.1 (Mark Mitchell, NY, USA) which measured all points on the force-deformation curve.

\section{Theoretical limit deformation}

The measured dependency between compressive force and deformation can be fitted by tangent curve (Eq. 2) which has been severally verified with the pressing of oilseed crops (Herak et al., 2010; 2011a; 2011b):

$$
F(x)=A \cdot[\tan (B \cdot x)]^{n} \quad \text { (Eq. 2) }
$$

Where $F(x)(\mathrm{N})$ is compressive force, $x(\mathrm{~mm})$ is deformation of mixture under compression loading, $A(\mathrm{~N})$ is force coefficient of mechanical behaviour, $B\left(\mathrm{~mm}^{-1}\right)$ is deformation coefficient of mechanical behaviour and $n(-)$ is exponent of the pressing function (Herák et al., 2011b). These coefficients of mechanical behaviour were determined using the Marquardt Levenberg process (Lourakis 2005; Marquardt 1963), with aid of software Mathcad 14 (PTC, Needham, USA). From this deformation (Eq. 3) can be expressed from equation (Eq. 2):

$$
x=\frac{1}{B} \arctan \left(\sqrt[n]{\frac{F(x)}{A}}\right)
$$

Solving the previous equation (Eq. 3) for compressive force approaching to the infinity it is possible to obtain equation (Eq. 4) for limit deformation $\delta(\mathrm{mm})$ expressed by deformation coefficient of mechanical behavior:

$$
\delta=\lim _{F(x) \rightarrow \infty} x=\frac{\pi}{2 \cdot B}
$$

\section{Oil point deformation ratio}

Oil point deformation ratio $R_{O P}$ (\%) (Eq. 5) was determined as ratio between deformation at oil point and theoretical limit deformation:

$$
R_{O P}=\frac{x_{o}}{\delta} \cdot 100
$$

\section{Maximal deformation ratio}

Maximal deformation ratio $R_{M D}$ (\%) (Eq. 6) was determined as ratio between maximal deformation and limit deformation:

$$
R_{M D}=\frac{x_{\max }}{\delta} \cdot 100
$$




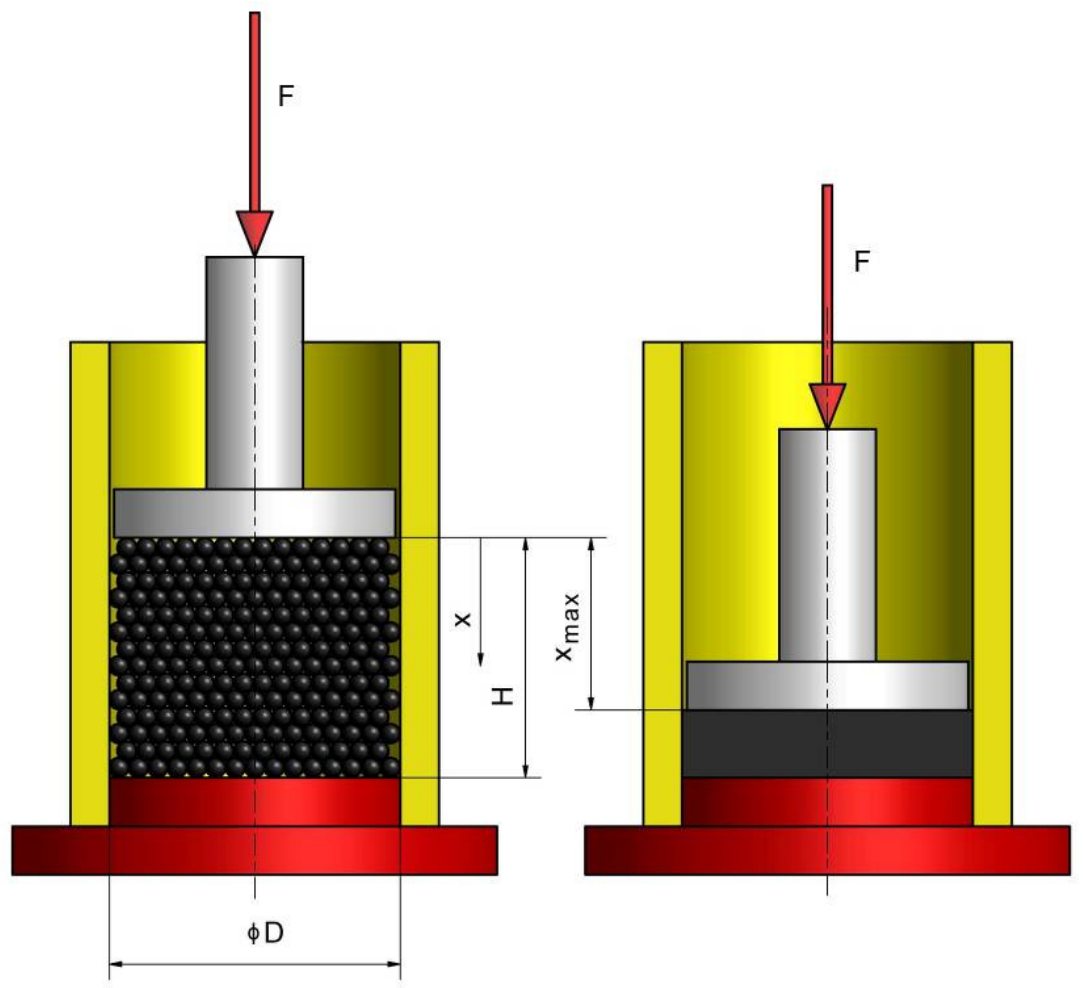

Fig. 1. Scheme of pressing equipment (H-height of seeds in the pressing vessel)

\section{Energy ratio}

Energy ratio $R_{E}$ (\%) (Eq. 7) was determined as ratio between energy at oil point and maximal deformation energy:

$$
R_{E}=\frac{E_{o}}{E} \cdot 100
$$

\section{Results and discussion}

The dependency between compressive force and deformation characteristic of pressed seed mixtures of rape, sunflower and jatropha are presented in Fig. 2. The results presented in (Tab. 2) show the measured parameters of the pressed seeds. Statistical analysis of the determined amounts (Tab. 3) using software MathCAD 14 were significant where the values of $\mathrm{F}_{\text {crit }}$ were higher than $\mathrm{F}_{\text {ratio }}$ values and amounts of $\mathrm{P}_{\text {value }}$ were higher than significance level 0.05 and also high values of coefficients of determination $\mathrm{R}^{2}$. In addition from the results of this study, the tangent curve equation (Eq. 2) (Herak et al., 2010; 2011a; 2011b) comparing with the measured dependency, described ac-

Tab. 2. Determined mechanical properties of seeds pressed mixture, data in the table are means \pm SD

\begin{tabular}{ccccccc}
\hline Oilseeds & $\begin{array}{c}\mathrm{x}_{\max } \\
(\mathrm{mm})\end{array}$ & $\begin{array}{c}\mathrm{x}_{\mathrm{o}} \\
(\mathrm{mm})\end{array}$ & $\begin{array}{c}\delta \\
(\mathrm{mm})\end{array}$ & $\begin{array}{c}\mathrm{F}_{\mathrm{o}} \\
(\mathrm{kN})\end{array}$ & $\begin{array}{c}\mathrm{E}_{\mathrm{o}} \\
(\mathrm{J})\end{array}$ & $\begin{array}{c}\mathrm{E} \\
(\mathrm{J})\end{array}$ \\
\hline Rape & $57.5 \pm 1.2$ & $52.5 \pm 0.7$ & $60.1 \pm 0.5$ & $83.3 \pm 4.2$ & $811 \pm 15$ & $1519 \pm 25$ \\
Sunflower & $50.6 \pm 1.0$ & $39.3 \pm 0.8$ & $52.7 \pm 0.8$ & $31.4 \pm 3.7$ & $372 \pm 20$ & $1294 \pm 28$ \\
Jatropha & $59.2 \pm 1.8$ & $49.2 \pm 1.0$ & $66.5 \pm 1.1$ & $38.3 \pm 4.8$ & $505 \pm 27$ & $1506 \pm 27$ \\
\hline
\end{tabular}

$\mathrm{x}_{\text {max }}$-true deformation, $\mathrm{x}_{\mathrm{o}}$ - deformation at oil point, $\delta$-limit deformation, $\mathrm{F}_{\mathrm{o}}$-compressive force at oil point, $\mathrm{E}_{\mathrm{o}}$-deformation energy at oil point,

E-maximal deformation energy

Tab. 3. Data of statistical analyzes for level of significance 0.05

\begin{tabular}{|c|c|c|c|c|c|c|c|}
\hline Crops seeds & $\begin{array}{c}\text { A } \\
(\mathrm{N}) \\
\end{array}$ & $\begin{array}{c}\mathrm{B} \\
\left(\mathrm{mm}^{-1}\right) \\
\end{array}$ & $\begin{array}{l}N \\
(-)\end{array}$ & $\begin{array}{l}\mathrm{F}_{\text {crit }} \\
(-)\end{array}$ & $\begin{array}{c}\mathrm{F}_{\text {ratio }} \\
(-)\end{array}$ & $\begin{array}{c}P_{\text {value }} \\
(-)\end{array}$ & $\begin{array}{l}R^{2} \\
(-) \\
\end{array}$ \\
\hline Rapeseeds & 17.495 & 0.026 & 1 & 3.978 & $3.576 \cdot 10^{-3}$ & 0.952 & 0.998 \\
\hline Sunflower & 16.237 & 0.030 & 1 & 3.986 & 0.011 & 0.916 & 0.991 \\
\hline Jatropha & 7.519 & 0.024 & 2 & 3.967 & $4.886 \cdot 10^{-3}$ & 0.944 & 0.998 \\
\hline
\end{tabular}

A-force coefficient of mechanical behaviour, B-deformation coefficient of mechanical behaviour, $n$-exponent of the compressive function,

$\mathrm{F}_{\text {ratio }}$-value of the $\mathrm{F}$ test, $\mathrm{F}_{\text {crit }}$-critical value that compares a pair of models, $\mathrm{P}_{\text {value }}$-the significance level at which it can be rejected the hypothesis of equality of models, $\mathrm{R}^{2}$-coefficient of determination 
230

curately the dependency between the compressive force and deformation characteristic of the pressed seeds.

On the deformation curve of the pressed seeds (Fig. 2), the positions of oil point of the various seeds, that is, the first leakage of oil from the pressing vessel have been identified and their determined amounts of compressive force, deformation and deformation energy at oil point are also presented in Tab. 2. In terms of deformation at oil point, the highest amount was rapeseeds followed by jatropha seeds and then sunflower seeds. However, considering true deformation and limit deformation values, the trend slightly changed. Jatropha recorded the highest value followed by rapeseeds and lastly sunflower seeds. This change of results suggest that at oil point, the size of seeds does not influence the extent of deformation rather it could be the seeds inherent characteristics and the influence of moisture content which enlarges the area under the force-deformation curve thereby increasing the amounts of seed deformation at oil point. Comparing the oil point deformation ratios (Fig. 3) of the various seeds, it was found that rapeseeds mixture used the greatest amount of compressive force followed by sunflower and jatropha. The results of deformation energy at oil point and true maximal deformation of the pressed seed mixtures are given in Tab 2. From the results, rapeseeds showed the greatest energy requirement of 53\% input energy followed by jatropha and sunflower. Further, the determined amounts at oil point in the present study were higher compared to different studies reported in the literature (Blahovec and Reznicek, 1980; Danilov, 1976; Faborode and Favier, 1996; Fomin, 1978; Fornal et al., 1994; Herak et al., 2010; Koegel et al., 1973; Mrema and Mc Nulty, 1985; Sukumaran and Singh, 1989; Singh et al., 1984). Comparing maximal deformation ratios (Fig. 3 ) of the pressed seed mixtures where it can be assumed that appropriate compression can be achieved, rapeseeds and sunflower seeds showed $95 \%$ greater performance

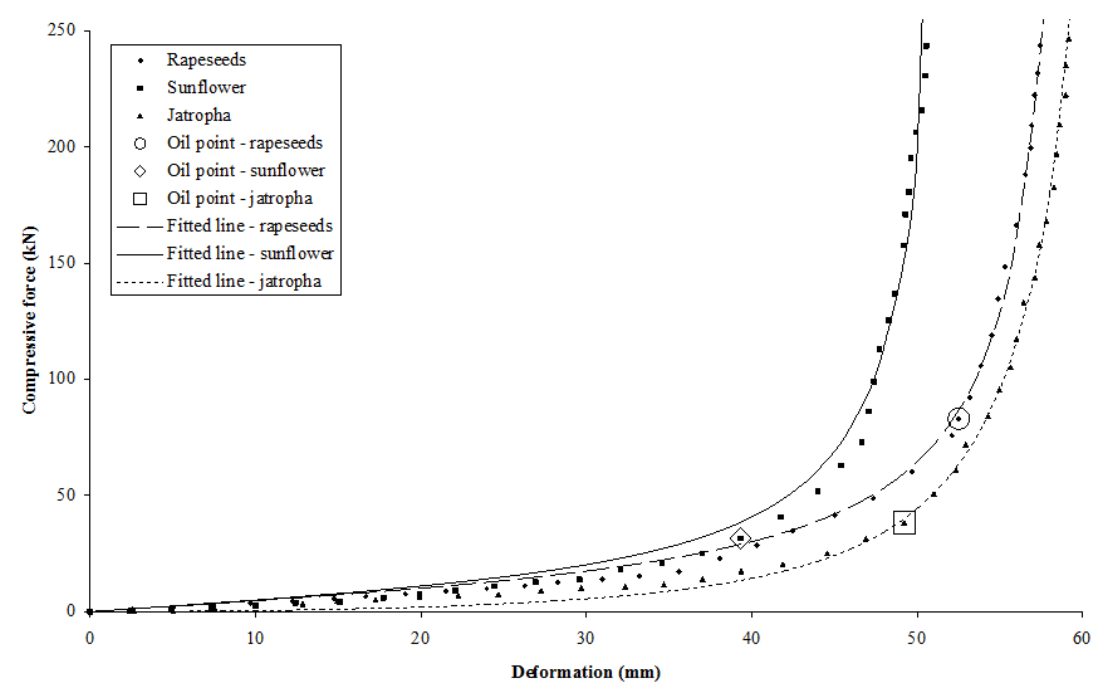

Fig. 2. Deformation characteristics with marked oil points

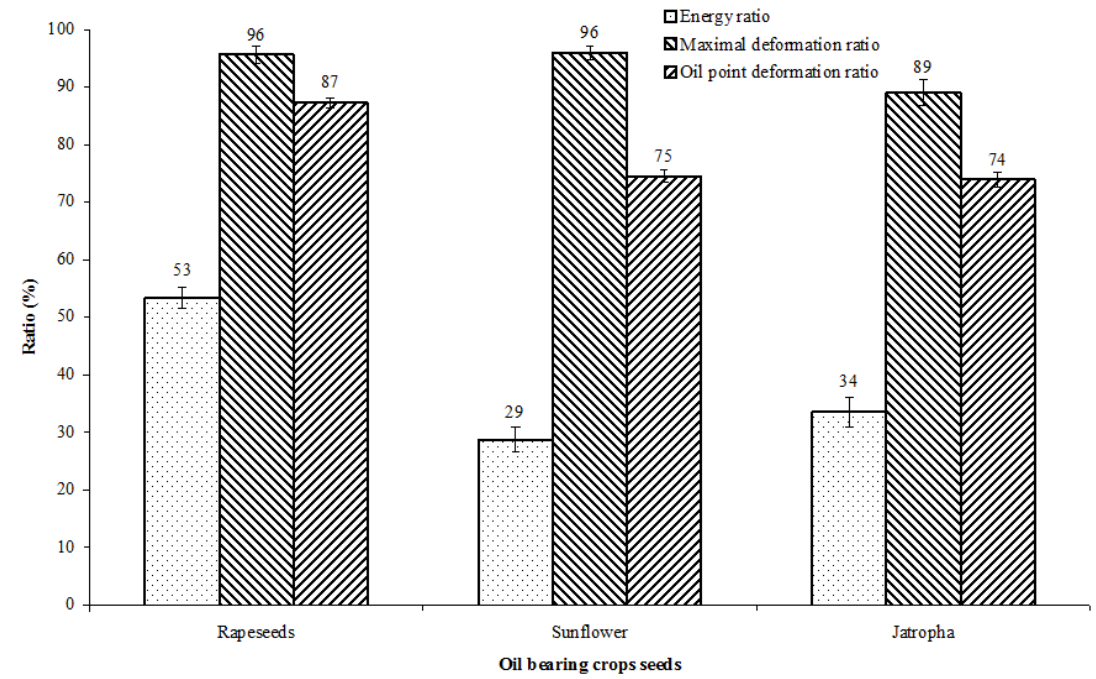

Fig. 3. Energy ratio, maximal deformation ratio and oil point deformation ratio of the pressed oilseeds; the marks at the columns of the ratio indicate the standard deviation 
than jatropha seeds. This could be due to the different inherent seed characteristics hence different mechanical behaviour. The value of maximal deformation ratio of jatropha seeds also suggest that a higher compressive force is needed to achieve appropriate compression than the force applied in this study.

From the physical properties of the pressed seed mixtures Tab. 1 , it is seen that moisture content is an important parameter which can influence the mechanical behaviour of oilseeds, that is, moisture content can cause transformation of deformation characteristic (Karaj and Muller, 2010; Sirisomboon et al., 2007; Unal et al., 2009) and thus change the maximal and limit deformation as well as deformation energy (Blahovec and Reznicek, 1980; Herak et al., 2010; Kabutey et al., 2011; Koegel et al., 1973). Porosity can also influence the mechanical behaviour of oilseeds (Fomin, 1978; Herak et al., 2011a).

Based on the results, pressing of the rapeseeds mixture demanded more energy compared to jatropha and sunflower. Comparing this results with previous studies on the mechanical behaviour of one seed under compression loading where unit deformation energy, rupture force and rupture compressive stress were determined, the results obtained in the present study were in agreement with the pressing of rapeseed (Izli et al., 2009; Unal et al., 2009), jatropha seed (Karaj and Muller, 2010; Sirisomboon et al., 2007), sunflower seed (Gupta and Das, 2000; Perez et al., 2007). Also the position of oil points on the deformation characteristics of the various oilseeds corresponds to similar studies reported by (Faborode and Favier, 1996; Figueiredo et al., 2011; Sayyar et al., 2009) and also the shapes of deformation characteristic are significant to the characteristics described by (Gupta and Das, 2000; Herak et al., 2010; Kabutey et al., 2011; Rusinek et al., 2007),

\section{Conclusions}

Among the selected oilseed crops, rapeseed obtained the greatest amount of deformation energy followed by jatropha and then sunflower. Their respective deformation energy values showed the energy requirement for obtaining the oil under linear pressing experiment. The tangent curve equation having been established in previous studies also described accurately the deformation characteristics of the selected oilseeds. The information provided in this article would be relevant for the optimization of the mechanical method involving screw presses or extruders for processing of oil from oilseed crops.

\section{Acknowledgement}

This research is supported by the Internal Grant Agency of the Czech University of Life Sciences Prague, Czech Republic.

\section{References}

Blahovec J, Reznicek R (1980). Frakcionace pice (Fractionation of the forage). Prague, VSZ v Praze, $370 \mathrm{p}$.

Blahovec J (2008). Agromaterials. CULS Prague, 102 p.

Danilov VI (1976). Energy performance and efficiency of the extrusion disintegration process of green forage. Proceeding institute of agriculture machine, Rostov on Don, Izdatelstvo Rostovskovo universiteta, $35 \mathrm{p}$.

Figueiredo AK, Baumler E, Riccobene IC, Nolasco SM (2011). Moisture-dependent engineering properties of sunflower seeds with different structural characteristics. J Food Eng 58-65 p.

Faborode MO, Favier JF (1996). Identification and Significance of the Oil-point in Seed-oil Expression. J Food Eng Res 65:335-345.

Fomin VI (1978). Wet fractionation of green forage. Rostov on Don, Izdatelstvo Rostovskovo universiteta, $160 \mathrm{p}$.

Fornal J, Sadowska J, Jaroch R, Kaczynska B, Winnicki T (1994). Effect of drying of rapeseeds on their mechanical properties and technological usability. Int Agrophys 8:215-224.

Gupta RK, Das SK (1997). Physical properties of sunflower seeds. J Agri Eng Res 66:1-8.

Gupta RK, Das SK (2000). Fracture resistance of sunflower seed and kernel to compressive loading. J Food Eng 46:1-8.

Herak D, Gurdil G, Sedlacek A, Dajbych O, Simanjuntak S (2010). Energy demands for pressing Jatropha curcas L. seeds. Biosyst Eng 106:527-534.

Herak D, Kabutey A, Sedlacek A (2011a). Mathematical description of rape seeds' (Brassica napus L.) mixture mechanical behavior under compression loading. Sci Agr Bohemica 42:31-36.

Herak D, Kabutey A, Sedlacek A, Gurdil G (2011b). Tangent curve utilization for description of mechanical behaviour of pressed mixture. Res in Agric Eng 57:13-18.

Herak D, Kabutey A, Sedlacek A, Gurdil G (2012). Mechanical behaviour of several layers of selected plant seeds under compression loading. Res in Agric Eng 58:24-29.

Isik E, Izli N (2007). Physical properties of sunflower seeds (Helianthus annuus L.). Internat J Agric Res 2:677-686.

Izli N, Unal H, Sincik M (2009). Physical and mechanical properties of rapeseed at different moisture content. Int Agrophys 23:137-145.

Kabutey A, Herak D, Sedlacek A (2011). Behaviour of different moisture contents of Jatropha curcas L. seeds under compression loading. Res in Agric Eng 57:72-77.

Karaj S, Muller J (2010). Determination of physical, mechanical and chemical properties of seeds and kernel of Jatropha curcas L. Ind Crop and Prod 32:29-138.

Khodabakhshian R, Emadi B, Abbaspour Fard MH, Saiedirad MH (2010). Mechanical properties of sunflower seeds and its kernel, Azargol variety as a Case Study under compression 
232 loading. J of Agric Sci and Tech, 1 p.

Koegel RG, Fomin VI, Bruhn HD (1973). Roller maceration and fractionation of forage, Transactions of the ASAE 16:236-240.

Lourakis MIA (2005). A Brief Description of the LevenbergMarquardt Algorithm Implemened by Levmar. ICS FORTH, Heraklion, 2 p.

Marquardt DW (1963). An Algorithm for the Least-Squares Estimation of Nonlinear Parameters. SIAM J Appl Math 11:431-441.

Mrema GC, Mc Nulty PB (1985). Mathematical model of mechanical oil expression from oilseeds. J Agric Eng Res 31:361-370.

Petru M, Novak O, Herak D, Simanjuntak S (2012). Finite element method model of the mechanical behaviour of Jatropha curcas L. seeds under compression loading. Biosyst Eng 111:412-421.

Perez EE, Crapiste GH, Carelli AA (2007). Some Physical and Morphological Properties of Wild Sunflower Seeds. Biosyst Eng 96:41-45.
Rusinek R, Molenda M, Sykut J, Pits N, Tys J (2007). Uniaxial compression of rapeseed using apparatus with cuboid chamber. Acta Agrophysica 10:677-685.

Sayyar S, Aidin ZZ, Yunus R, Muhammad A (2009). Extraction of Oil from Jatropha Seeds-Optimization and Kinetics. Am J Appl Sci 6:1390-1395.

Singh MS, Farsaie A, Stewart LE, Douglass LW (1984). Development of mathematical models to predict sunflower oil expression. Transaction of ASAE 27:1190-1194.

Sirisomboon P, Kitchaiya P, Pholpho T, Mahuttanyavanitch W (2007). Physical and mechanical properties of Jatropha curcas L. fruits, nuts and kernels. Biosyst Eng 97:201-207.

Sukumaran CR, Singh BPN (1989). Compression of a bed of rapeseeds: The oil-point. J Agric Eng Res 42:77-84.

Unal H, Sincik M, Izli N (2009). Comparison of some engineering properties of rapeseed cultivars. Ind Crop Prod 30:131-136. 